\title{
Testosterone Enhancement of the Nerve Cell Body Response to Injury: Evidence Using in situ Hybridization and Ribosomal DNA Probes
}

\author{
Nancy B. Kinderman and Kathryn J. Jones \\ Departments of Physical Therapy, Anatomy, and Cell Biology, University of Illinois at Chicago, Chicago, Illinois 60612
}

In axotomized peripheral motoneurons capable of successful regeneration, one of the earliest morphological indicators of the injury response occurs within the nucleolus. In the initial part of this investigation, we mapped the nucleolar response of injured adult hamster facial motoneurons from a molecular perspective, utilizing in situ hybridization and ribosomal DNA probes complementary to stable rRNA. Recently, we have discovered that the gonadal steroid, testosterone propionate (TP), accelerates recovery from facial paralysis in the hamster by increasing the rate of regeneration of the fastest regrowing axons. In the second part of this study, the hypothesis that TP accomplishes these effects on facial nerve regeneration through an enhancement of the nerve cell body response to injury was tested using in situ hybridization and rDNA probes. Adult intact male hamsters were subjected to right facial nerve axotomies at the stylomastoid foramen. One-half of the axotomized animals received subcutaneous implants of TP, with the remainder sham implanted. In situ hybridization with tritiated rDNA probes was accomplished and levels of hybridizable rRNA assessed both qualitatively and quantitatively. Axotomy alone induced an upregulation in rRNA levels, with peak changes occurring by $24 \mathrm{hr}$ postoperative and continuing through postoperative day 4 . These molecular changes in the nucleolar response preceded, by a full day, any morphological signs of the nucleolar reactive pattern previously found in this cell type, and, as such, point to the usefulness of in situ hybridization as a tool to identify the earliest events associated with the axon reaction. A secondary smaller increase in rRNA levels was observed during the later stages of regeneration. TP significantly augmented the ribosomal response to injury, with levels of rRNA increased as early as $6 \mathrm{hr}$ and the magnitude of the response greater than that occurring following axotomy alone. These results provide the first mechanistic step in the identification of the cellular processes underlying gonadal steroid augmentation of neuronal reparative processes. We conclude that TP accelerates the "switch" from a normal to a reparative state and suggest that this priming effect may be causally related to

\footnotetext{
Received Aug. 4, 1992; revised Oct. 6, 1992; accepted Oct. 12, 1992.

We thank Brian Hendrickson and Peter Farmer for their technical assistance. This work was supported by NIH Grant NS-28238 to K.J.J.

Correspondence should be addressed to Dr. Kathryn J. Jones, Department of Physical Therapy (M/C 898), University of Illinois at Chicago, 1919 West Taylor Street, Chicago, IL 60612.

Copyright (C) 1993 Society for Neuroscience $0270-6474 / 93 / 131523-10 \$ 05.00 / 0$
}

the differential effects of TP on the regenerative properties of this cell type.

[Key words: gonadal steroid, neurotrophic agent, nerve regeneration, nucleolar reactive pattern]

Axon injury induces a coordinated series of profound structural and metabolic alterations in the adult nerve cell body that has been collectively referred to in the literature under a variety of names, including chromatolysis or chromalytic response, retrograde reaction, axon reaction, and the nerve cell body response to injury (Lieberman, 1971; Grafstein, 1975). Among the most pronounced morphological changes are chromatolysis, or dissolution of the rough endoplasmic reticulum, somal and perikaryal swelling, nuclear eccentricity, and nucleolar hypertrophy. Evidence obtained from a variety of systems and technical approaches has demonstrated that the nucleolus, site of polymerase I-directed ribosomal RNA transcription and processing, is one of the earliest cellular components to be affected by distal lesion of the axon (Watson, 1968; Lieberman, 1971; Jones and LaVelle, 1986a, 1987). Large, protein secretory cells such as mammalian motor neurons contain the most highly evolved "reticulated" nucleoli (Busch and Smetana, 1970). As such, stimulus-induced changes in neuronal nucleolar structure provide a cytological index of the metabolic state of the cell (Busch and Smetana, 1970). As measured biochemically and autoradiographically, axotomized neurons displaying many of the aforementioned structural effects in rRNA-containing organelles generally have concomitant alterations in polymerase IIdirected mRNA and protein synthesis that are associated with survival and regrowth of the axon (Lieberman, 1974; New et al., 1989; Oblinger et al., 1989).

From a morphological perspective, one of the most well-characterized nerve cell types in which the injury response has been investigated is the hamster facial motor neuron (HFMN; LaVelle and LaVelle, 1984). Histological, ultrastructural, and morphometric analyses of the axon reaction have been accomplished across the lifespan of the cell (LaVelle and LaVelle, 1958a,b, 1984; Kinderman and LaVcllc, 1976; Jones and LaVclle, 1986a,b, 1987; Clark et al., 1990, 1991). In the adult, a cytological and temporal framework of the response of those neurons to axotomy has emerged that indicates that the peak of the nuclear and nucleolar response occurs within the first $48 \mathrm{hr}$, and the peak of the cytoplasmic response occurs at $4 \mathrm{~d}$. In addition, virtually $100 \%$ of adult HFMNs are capable of surviving axotomy and initiating successful regeneration. The pattern of the axon reaction in HFMN appears to occur independently of the 
target muscles, such that the HFMN will undergo a defined reactive sequence and return to a "normal" state whether or not reconnection is allowed to occur.

The nucleolar reaction pattern in axotomized HFMN has been ultrastructurally characterized both developmentally and in the adult (Kinderman and LaVelle, 1976; Jones and LaVelle, 1986a; Clark et al., 1990, 1991). Axotomy during early development results in progressive nucleolar segregation similar to that observed under conditions of rRNA downregulation. With increasing age and survival capabilities, the nucleolar reactive pattern described gradually becomes less pronounced and is subsequently replaced by nucleolar hypertrophy and a reactive pattern similar to that seen under conditions associated with an increase in the production of rRNA. These results have led to the hypothesis that a key step in the ability of neurons to survive axotomy and successfully regenerate occurs at some point in rRNA transcription and/or processing (Clark et al., 1991). In the initial part of this investigation, we addressed this hypothesis by mapping the nucleolar response of injured adult HFMN from a molecular perspective, utilizing rDNA probes complementary to stable rRNA (Chikaraishi et al., 1983) and in situ hybridization.

Across the vertebrate brain and spinal cord, many populations of neurons, including most cranial and spinal motor neurons, contain steroid receptors (Pfaff and Keiner, 1973; Yu and McGinnis, 1986; Simerly et al., 1990). Neuroendocrine work over the past decade has established that steroid hormones act, presumably via a receptor-mediated mechanism, to affect trophically many aspects of normal neuronal functioning (cf. Jones, 1993). Different types of hormones, including gonadal steroids, glucocorticoids, and thyroid hormones, have been employed clinically and/or experimentally in the injured or diseased nervous system (cf. Jones, 1993). Using the HFMN, which contains androgen receptors, as an experimental model, we have recently shown that testosterone accelerates recovery from facial paralysis induced by facial nerve crush (Kujawa et al., 1989; Kujawa and Jones, 1990) and that these effects of the steroid on recovery occur through an increase in the rate of regeneration, but not a shortening in the initial delay of sprouting (Kujawa et al., 1991). From these results as well as the evidence obtained in a preliminary investigation of the actions of testosterone on the injured facial neuron (Kinderman and Jones, 1991), it appears that testosterone primes the cell body by altering the early genomic response to injury. In the second part of this study, we extended our investigation of the direct actions of gonadal steroids on injured neurons by assaying the effects of testosterone on the ribosomal system in axotomized facial motoneurons across the entire regenerative period. The data lead us to define gonadal steroids as motor neuron trophic factors capable of significantly modulating components of the injury response critical to cell viability and successful regeneration.

\section{Materials and Methods}

Surgical procedures and hormone administration. All surgical procedures were completed in accordance with National Institutes of Health guidelines on the care and use of laboratory animals for research purposes. Adult intact male hamsters $(60 \mathrm{~d}$ old, $100 \mathrm{gm}$ body weight; Harlan-Sprague-Dawley, Indianapolis, IN) were used in these experiments. Each animal was anesthetized by intraperitoneal injection of Nembutal $(50 \mathrm{mg} / \mathrm{ml}, 0.18 \mathrm{ml} / 100 \mathrm{gm}$ body weight), and the right facial nerve was severed at its exit from the stylomastoid foramen and proximal to the posterior auricular branch (Jones and LaVelle, 1986a). Immediately following axotomy, half of the animals were implanted with two Silastic capsules containing $100 \%$ crystalline testosterone propionate (TP; 0.062 inch i.d. $\times 0.095$ inch o.d. equilibrated in sterile physiological saline) while the other half received sham implants (Krey and McCrinnis, 1990; Kujawa et al., 1991). All groups had between three and five animals, with a total of 67 hamsters.

In situ hybridization. At the end of postoperative times of 6 or $18 \mathrm{hr}$, or $1,2,4,6,7,8,12$, or $14 \mathrm{~d}$, the animals were killed by decapitation. The brains were rapidly removed and blocked to include the facial nucleus, and then fresh frozen as described elsewhere (Hawkins and Mans, 1989). Cryostat sections throughout the length of the facial nucleus were collected on chrome-alum-subbed glass slides and then immersion fixed in $4 \%$ paraformaldehyde in PBS for $1.5 \mathrm{hr}$. The slides were rinsed twice in $100 \mathrm{mM}$ PBS for $5 \mathrm{~min}$ and in $5 \mathrm{~mm}$ dithiothreitol for $5 \mathrm{~min}$, dehydrated in graded ethanols, and left to dry overnight in a vacuum desiccator. All slides were then stored at $-70^{\circ} \mathrm{C}$. Ribosomal DNA (rDNA) probes complementary to the 28S rRNA species (Chikaraishi et al., 1983) were received as a gift from Drs. Dona Chikaraishi and Chris Harrington (Tufts University) and nick translated with ${ }^{3} \mathrm{H}$ dCTP (30 Ci/mmol; ICN) and ${ }^{3} \mathrm{H}-\mathrm{dTTP}(60 \mathrm{Ci} / \mathrm{mmol}$; ICN). Prior to each in situ hybridization run, the sections were brought to room temperature. Prehybridization, hybridization, and posthybridization steps were accomplished as previously described (Jones et al. 1986a, 1990). The slides were subsequently rinsed twice in $2 \times$ saline-sodium citrate (SSC) for 10 min and washed overnight in 2 liters of $0.5 \times$ SSC containing $5 \mathrm{~mm}$ dithiothreitol. After final rinsing in successive solutions of ammonium acetate:ethanol, the slides were dried in a desiccator.

Standard procedures for liquid emulsion autoradiography were followed (Jones et al., 1986a). Briefly, under safelight conditions, randomly selected pairs of slides from hormone-treated and non-hormone-treated groups were dipped in Kodak NTB-2 emulsion diluted 1:1 with sterile water and allowed to dry in a light-tight box containing desiccant for 2 $\mathrm{hr}$. The slides were then transferred to opaque slide boxes containing desiccant, sealed with black tape, and stored at $4^{\circ} \mathrm{C}$. At the appropriate exposure time (between 4-6 weeks), as determined by test slides, all slides were developed, lightly stained with cresyl violet, and coverslipped.

Grain counting procedures. Using a computerized image analysis system (SMI-MicroComp, Atlanta, GA), quantitative evaluation of neurons within both the right (operated) and left (unoperated) facial nuclei in the same section was determined. Since, in this system as well as others, nucleolar alterations on the unoperated side due to contralateral work hypertrophy do not occur (Jones and LaVelle, 1986a), comparisons could be accomplished utilizing the unoperated side as a control. The advantage of this approach is that the axotomized and control neurons are processed in an identical manner throughout the experiment. This includes anesthesia and handling of the animal as well as all hybridization and autoradiographic procedures. While it is generally necessary to subtract background levels of labeling in order to correct for nonspecific hybridization, we have found the background levels of labeling following in situ hybridization with the rDNA probes to be consistently negligible (Jones et al., 1986a, 1990). Grain counts and somal areas from 25-50 neurons containing a nucleus and with a clearly defined somal contour were collected from one or more sections for both the axotomized and control facial nuclear groups, and the data averaged such that three mean values were obtained: number of grains per cell representing levels of hybridizable rRNA within each neuron, neuronal area in square micrometers, and grain density (number of grains per square micrometer of somal area) representing concentration of hybridizable rRNA within each neuron (Jones et al., 1986a, 1990). The data were then expressed as mean ratios of axotomized versus unoperated control values, as has been previously described (Wong and $\mathrm{Ob}-$ linger, 1990). Comparisons between ratios of TP-treated, axotomized animals and non-hormone-treated, axotomized animals were subsequently accomplished. Since steroid hormones regulate cellular rRNA normally (Jones et al., 1990), this approach eliminated any general metabolic effects of TP on rRNA levels that were unrelated to axotomy. Furthermore, since the numbers of animals/slides were so extensive, this approach allowed a full, temporal analysis of the effects of axotomy versus axotomy plus TP on the regulation of the ribosomal system in facial neurons. Statistical analysis of somal area measurements was accomplished using two-way ANOVA and the Student-Newman-Keuls test at $p<0.05$ (Sokal and Rohlf, 1981).

Northern blot analysis. Total RNA was isolated from normal facial tissue by the procedure of Chomczynski and Sacchi (1987), electrophoretically separated on a $1 \%$ agarose denaturing gel, stained with ethidium bromide, and photographed, and $10 \mu \mathrm{g}$ was blotted onto $\mathrm{Ny}$ - 
tran membrane. The blots were hybridized with ${ }^{32} \mathrm{P}$-labeled rDNA probe as described elsewhere (Ausebel et al., 1989), washed to a final stringency of $0.1 \times \mathrm{SSC}, 0.1 \% \mathrm{SDS}$ at $65^{\circ} \mathrm{C}$ for $20 \mathrm{~min}$, and briefly exposed to $\mathrm{x}$-ray film, and the film was then developed.

\section{Results}

Specificity of the $28 S$ rDNA probe. As demonstrated in Figure $1 a$, both the $28 \mathrm{~S}$ and $18 \mathrm{~S}$ rRNA species are present in abundant quantity in normal hamster facial tissue. Levels of $28 \mathrm{~S}$ rRNA are slightly higher that those of the $18 \mathrm{~S}$ species, which is in agreement with quantitative data of absolute pool sizes of the various rRNA species in rat liver cells (Dabeva et al., 1978). The $28 \mathrm{~S}$ rDNA probe hybridizes specifically to a single band representing the $28 \mathrm{~S}$ rRNA species (Fig. $1 b$ ), and not to the $18 \mathrm{~S}$ species or to other intermediate rRNA molecules of higher molecular weight. Again, this is in agreement with quantitative data demonstrating that pre-rRNA molecules that also contain $28 \mathrm{~S}$ sequences either exist in minute amounts or are not present under steady state conditions (Dabeva et al., 1978). Thus, the pattern of labeling generated with in situ hybridization in this study reflects the distribution of 28S rRNA, which forms the large stable ribosomal subunit in eukaryotes (Hadjiolov, 1985), with grains present overlying the nucleolus, site of rRNA transcription, the nucleoplasm, and Nissl substance (stacked rough endoplasmic reticulum) in the cytoplasm (see Fig. $2 a, b$ for examples). Such a grain pattern was consistently observed, along with relatively low background levels, in both experimental and control tissue and is in accordance with our previous in situ hybridization results obtained with this probe (Jones et al., 1986a, 1990).

Effects of facial nerve severance on ribosomal RNA in facial motoneurons. In adult HFMN, morphological signs of injury, in the form of chromatolysis, begin to appear within the first $24 \mathrm{hr}$ and are well advanced $4 \mathrm{~d}$ after severance of the facial nerve at the level of the stylomastoid foramen (LaVelle and LaVelle, 1958b). The nucleolar reactive pattern has been well characterized from both histological and ultrastructural perspectives (LaVelle and LaVelle, 1958a; Kinderman and LaVelle, 1976; McLoon and LaVelle, 1981; Jones and LaVelle, 1986a; Clark et al., 1991) and has been shown to peak within $48 \mathrm{hr}$ after axotomy. Therefore, the early postoperative times in this investigation were selected in order to analyze, from a molecular perspective, the initial axotomy-induced events occurring within this cell type. In addition, later postoperative time points coincident with regeneration and reinnervation were included as a second "wave" of metabolic activity associated with these later events has been described in the literature (Wells, 1987).

The effects of facial nerve severance, at the level of the stylomastoid foramen, on ribosomal RNA levels are illustrated by example in Figure 2 and quantitatively in Figure 3. In Figure $2 a$, a control facial motoneuron from the left, unoperated nuclear group is shown. The grain distribution is consistent with the cellular distribution of rRNA. In Figure $2 b-f$, axotomized facial motoneurons at $6 \mathrm{hr}$, and $1,2,8$, and $14 \mathrm{~d}$ postoperative are illustrated. At the earliest postoperative time point of $6 \mathrm{hr}$, few changes in labeling of axotomized neurons, relative to the controls, are seen. A progressive increase in the labeling of the axotomized neurons is evident at 1 and $2 \mathrm{~d}$ after axotomy, and again at $8 \mathrm{~d}$, with a return to control levels by $14 \mathrm{~d}$ postoperative. These changes were quantitatively substantiated using a computerized image analysis system to determine relative levels of hybridizable rRNA after axotomy, as compared to the unoperated side (Fig. 3). Levels of rRNA increased substantially be-

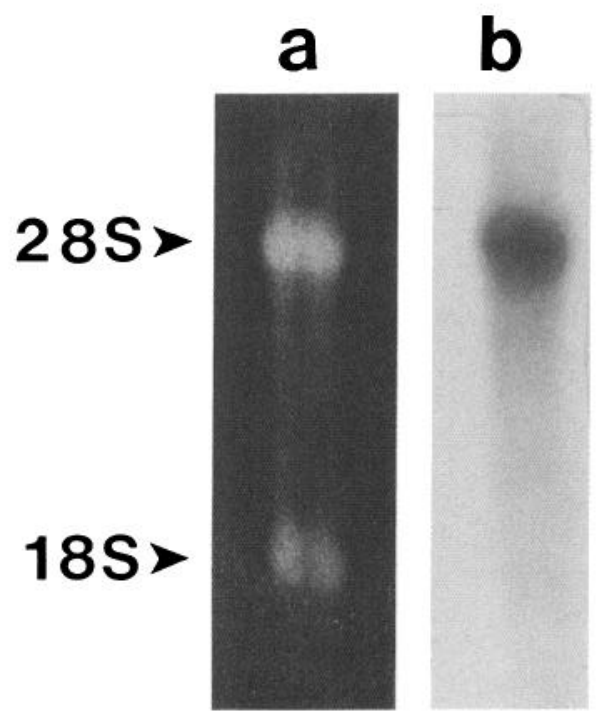

Figure 1. Northern blot analysis of probe specificity. Ten micrograms of total RNA isolated from hamster facial motoneurons were electrophoretically separated on a denaturing gel, blotted to Nytran, and hybridized with the $28 \mathrm{~S}$ rDNA probe. $a$, Ethidium bromide-stained gel. $b$, Autoradiogram of the Northern blot. The locations of the $28 \mathrm{~S}$ and $18 \mathrm{~S}$ rRNA species are indicated by arrowheads.

tween $18 \mathrm{hr}$ and $1 \mathrm{~d}$, peaked at $1 \mathrm{~d}$, and remained elevated through $4 \mathrm{~d}$ postoperative, with a decrease to below baseline at the end of the first postoperative week. A secondary, lesser increase above baseline was observed during the beginning of the second postoperative week, with a decrease to below baseline again occurring at the end of the second week. Thus, two separate phases of ribosomal activity were identified in the time period previously associated with regeneration in this cell type, with the initial phase the most pronounced in magnitude compared to the second and with both heightened levels lasting $4 \mathrm{~d}$ in duration.

In addition to the measurements of levels of rRNA, the effects of axotomy on the concentration of rRNA within each injured facial motoneuron were also assessed across the entire regenerative period. To accomplish this, measurements of somal area were first established using the computerized imaging system (Table 1). Consistent with previous histological assessments of the swelling reaction of axotomized facial neurons (LaVelle and LaVelle, 1958b), significant increases $(p<0.05)$ in neuronal area were initially observed at $1 \mathrm{~d}$ following facial nerve severance at the level of the stylomastoid foramen and remained significantly increased through postoperative day 4 . Neuronal area returned to control values after $4 \mathrm{~d}$, but significantly increased a second time at $8 \mathrm{~d}$ postoperative $(p<0.05)$. By the end of the second postoperative week, neuronal size had again returned to control values. Calculation of the concentration of rRNA levels in individual axotomized HFMN was accomplished by determining the grain density or number of grains per square micrometer of somal area, with the data subsequently expressed as ratios of experimental:control (Fig. 4). Changes in the concentration of rRNA were less dramatic than those of levels of rRNA, and followed a different, relatively delayed time course. An increase in rRNA concentration was initially observed at $1 \mathrm{~d}$ and peaked at $4 \mathrm{~d}$ postoperative, with a return to baseline near the end of the first postoperative week. A secondary increase in rRNA concentration in the axotomized neurons, relative to the controls, was seen at the beginning of the second 

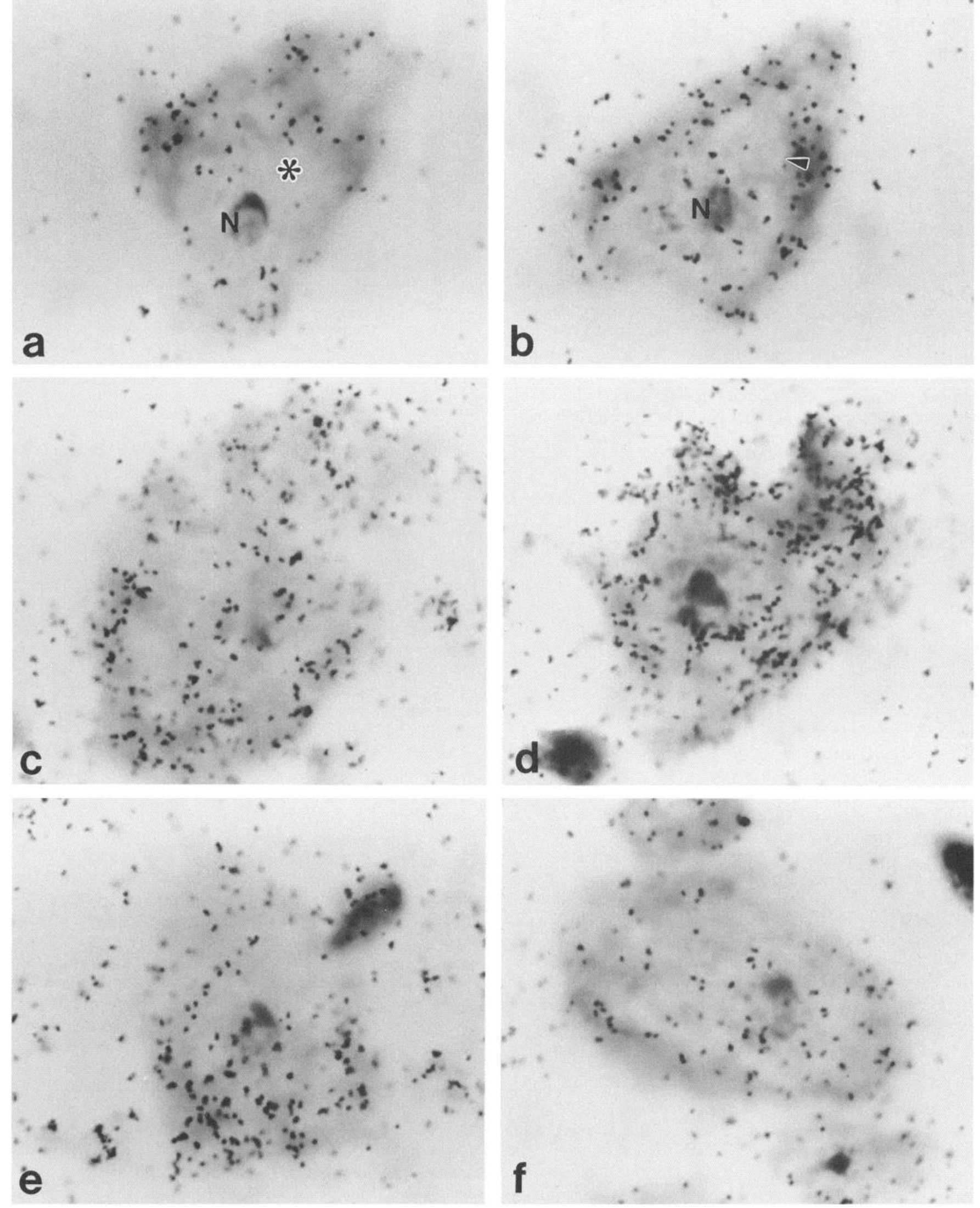

Figure 2. Autoradiographs of facial motoneurons following in situ hybridization with the $28 \mathrm{~S}$ rDNA probe. $a$, Control neuron from a nonhormone-treated animal. $N$, nucleolus; ${ }^{*}$, nucleus. $b-f$, Neurons from non-hormone-treated animals at $6 \mathrm{hr}$, and $1,2,8$, and $14 \mathrm{~d}$, respectively, after facial nerve severance. Arrowhead, nuclear boundary. 


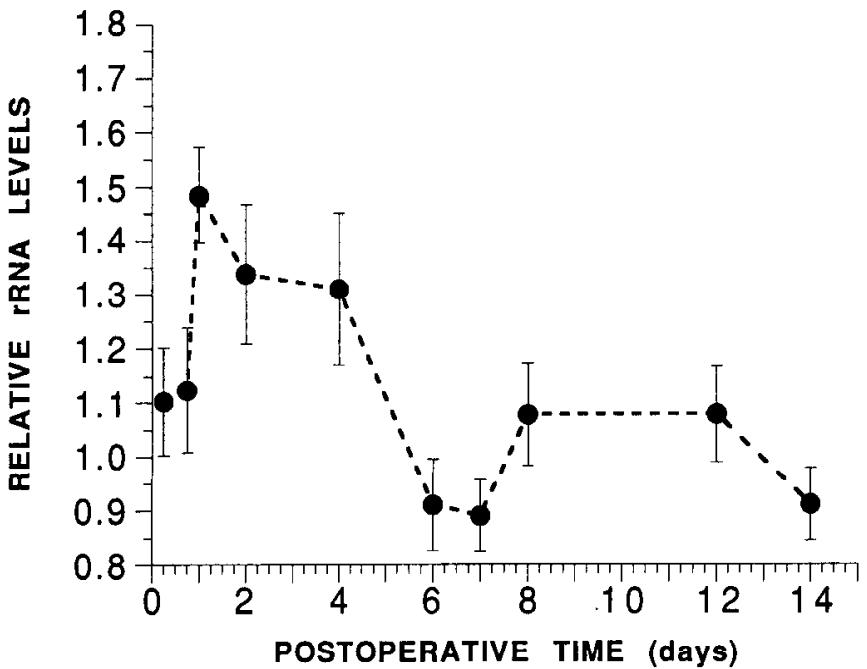

Figure 3. Effects of axotomy alone on levels of hybridizable rRNA in injured hamster facial motoneurons as a function of postoperative timc. The data are expressed as ratios of the averages of numbers of grains/ neuron from axotomized and control facial nuclear groups.

postoperative week. It appears, therefore, that axotomy produced two temporally distinct phases of increased rRNA activity, with both the amount and concentration of rRNA in the injured neurons altered.

Effects of TP plus facial nerve severance on ribosomal $R N A$ in facial motoneurons. In both non-neural and neural target tissue, gonadal steroids have been shown to regulate the ribosomal system rapidly in accordance with their trophic role in cellular metabolism (Whelly, 1985; Jones et al., 1990). In the second series of experiments in this study, the effects of subcutaneous administration of TP at the time of facial nerve severance, at the level of the stylomastoid foramen, on ribosomal RNA levels and concentration were determined. Qualitative evaluation of autoradiographs generated after in situ hybridization with the $28 \mathrm{~S}$ rDNA probe revealed a pronounced enhancement of the ribosomal response to injury (Fig. 5). In Figure $5 a$, a control facial motoneuron from the left, unoperated nuclear group of a hamster treated with TP for $6 \mathrm{hr}$ is shown. In Figure $5 b-f$, axotomized facial motoneurons from TP-treated animals at $6 \mathrm{hr}$, and 1,2,7, and $14 \mathrm{~d}$ postoperative are illustrated. At the earliest postoperative time point of $6 \mathrm{hr}$ (Fig. 5a), a dramatic increase in labeling, comparable to that observed $1 \mathrm{~d}$ after facial nerve severance in the non-hormone-treated animals, is evident (compare Figs. $2 a, 5 a$ ). A continued increase in labeling of the axotomized neurons from hormone-treated animals is evident at 1 and $2 \mathrm{~d}$, and again at $7 \mathrm{~d}$ after axotomy, with a return to control levels by $14 \mathrm{~d}$ postoperative (Fig. $5 b-f$ ). These changes were quantitatively substantiated using a computerized image analysis system to determine relative levels of hybridizable rRNA after axotomy, as compared to the unoperated side of hormonetreated animals (Fig. 6). This approach eliminated any separate, general effects of TP on facial motoneuron metabolism that were unrelated to axon injury. Levels of rRNA were increased as early as $6 \mathrm{hr}$ postoperative, to within $10 \%$ of the maximum observed with axotomy alone at $1 \mathrm{~d}$, with the peak in levels occurring at $2 \mathrm{~d}$ postoperative (Fig. 6). Following a rapid decline to below baseline, a secondary short-term increase in rRNA levels, reduced in magnitude relative to the initial phase, yet well above baseline, was observed at the end of the first post-

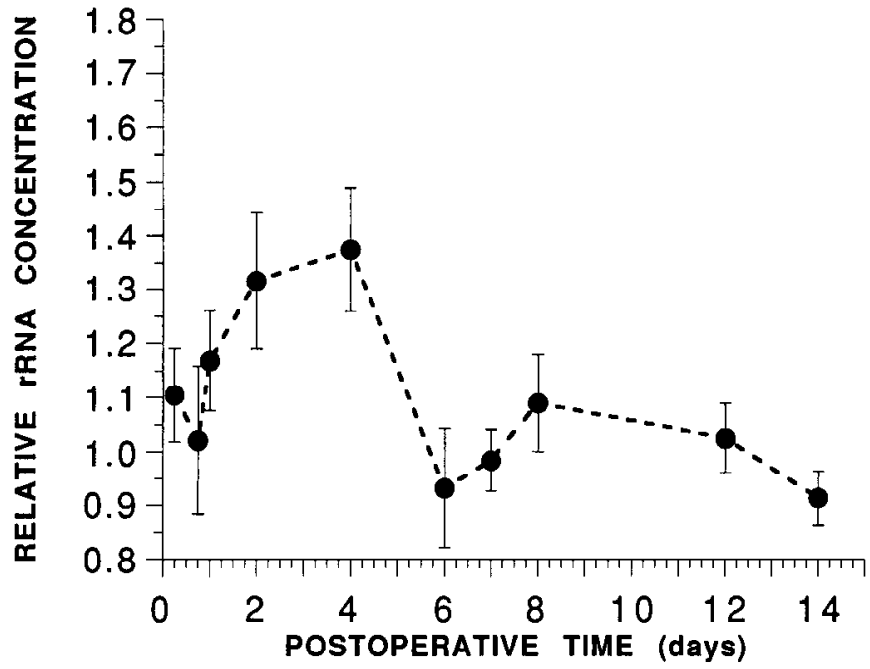

Figure 4. Effects of axotomy alone on the concentration of hybridizable rRNA in individual injured hamster facial motoneurons as a function of postoperative time. The data are expressed as ratios of the averages of grain density (number of grains per square micrometer somal area) from axotomized and control facial nuclear groups.

operative week. Interestingly, the secondary phase of rRNA activity after axotomy plus TP mirrored that of the first phase in a manner similar to that after axotomy alone. Both peaks in rRNA levels in the axotomized animals treated with TP occurred earlier than with axotomy alone, and were higher in magnitude and shorter in duration (1-2 d) than with axotomy alone.

The effects of axotomy plus TP on the concentration of rRNA within each injured facial motoneuron were also assessed across

\begin{tabular}{|c|c|c|c|c|}
\hline \multirow{2}{*}{$\begin{array}{l}\text { Post- } \\
\text { operative } \\
\text { time }\end{array}$} & \multicolumn{4}{|c|}{ Experimental group } \\
\hline & LC & RAx & $\mathrm{LC}+\mathrm{TP}$ & $\mathrm{RAx}+\mathrm{TP}$ \\
\hline $6 \mathrm{hr}$ & $\begin{array}{l}414 \\
( \pm 5)\end{array}$ & $\begin{array}{l}404 \\
( \pm 8.7)\end{array}$ & $\begin{array}{l}381 \\
( \pm 18)\end{array}$ & $\begin{array}{l}394 \\
( \pm 16)\end{array}$ \\
\hline $18 \mathrm{hr}$ & $\begin{array}{l}352 \\
( \pm 29)\end{array}$ & $\begin{array}{l}381 \\
( \pm 16)\end{array}$ & $\begin{array}{l}415 \\
( \pm 10)\end{array}$ & $\begin{array}{l}505^{*} \\
( \pm 19)\end{array}$ \\
\hline $1 \mathrm{~d}$ & $\begin{array}{l}375 \\
( \pm 38)\end{array}$ & $\begin{array}{l}481^{*} \\
( \pm 59)\end{array}$ & $\begin{array}{l}356 \\
( \pm 18)\end{array}$ & $\begin{array}{l}364 \\
( \pm 25)\end{array}$ \\
\hline $2 \mathrm{~d}$ & $\begin{array}{l}365 \\
( \pm 32)\end{array}$ & $\begin{array}{l}442^{*} \\
( \pm 25)\end{array}$ & $\begin{array}{l}356 \\
( \pm 26)\end{array}$ & $\begin{array}{l}337 \\
( \pm 11)\end{array}$ \\
\hline $4 d$ & $\begin{array}{l}396 \\
( \pm 17)\end{array}$ & $\begin{array}{l}454^{*} \\
( \pm 21)\end{array}$ & $\begin{array}{l}391 \\
( \pm 5)\end{array}$ & $\begin{array}{l}373 \\
( \pm 11)\end{array}$ \\
\hline $6 \mathrm{~d}$ & $\begin{array}{l}436 \\
( \pm 55)\end{array}$ & $\begin{array}{l}401 \\
( \pm 32)\end{array}$ & $\begin{array}{l}409 \\
( \pm 19)\end{array}$ & $\begin{array}{l}377 \\
( \pm 10)\end{array}$ \\
\hline $7 \mathrm{~d}$ & $\begin{array}{l}373 \\
( \pm 31)\end{array}$ & $\begin{array}{l}394 \\
( \pm 32)\end{array}$ & $\begin{array}{l}347 \\
( \pm 16)\end{array}$ & $\begin{array}{l}350 \\
( \pm 8)\end{array}$ \\
\hline $8 \mathrm{~d}$ & $\begin{array}{l}311 \\
( \pm 9)\end{array}$ & $\begin{array}{l}366^{*} \\
( \pm 10)\end{array}$ & $\begin{array}{l}328 \\
( \pm 9)\end{array}$ & $\begin{array}{l}316 \\
( \pm 4)\end{array}$ \\
\hline $12 \mathrm{~d}$ & $\begin{array}{l}320 \\
( \pm 7)\end{array}$ & $\begin{array}{l}349 \\
( \pm 43)\end{array}$ & $\begin{array}{l}442 \\
( \pm 39)\end{array}$ & $\begin{array}{l}432 \\
( \pm 7)\end{array}$ \\
\hline $14 \mathrm{~d}$ & $\begin{array}{c}345 \\
( \pm 3)\end{array}$ & $\begin{array}{l}348 \\
( \pm 7)\end{array}$ & $\begin{array}{l}391 \\
( \pm 4)\end{array}$ & $\begin{array}{l}429 \\
( \pm 6)\end{array}$ \\
\hline
\end{tabular}

$\overline{R A x}$, right side axotomy; LC, left side control; $R A x+T P$, right side axotomy plus TP; LC + TP, left side control plus TP.

* Significant at $p<0.05$. 

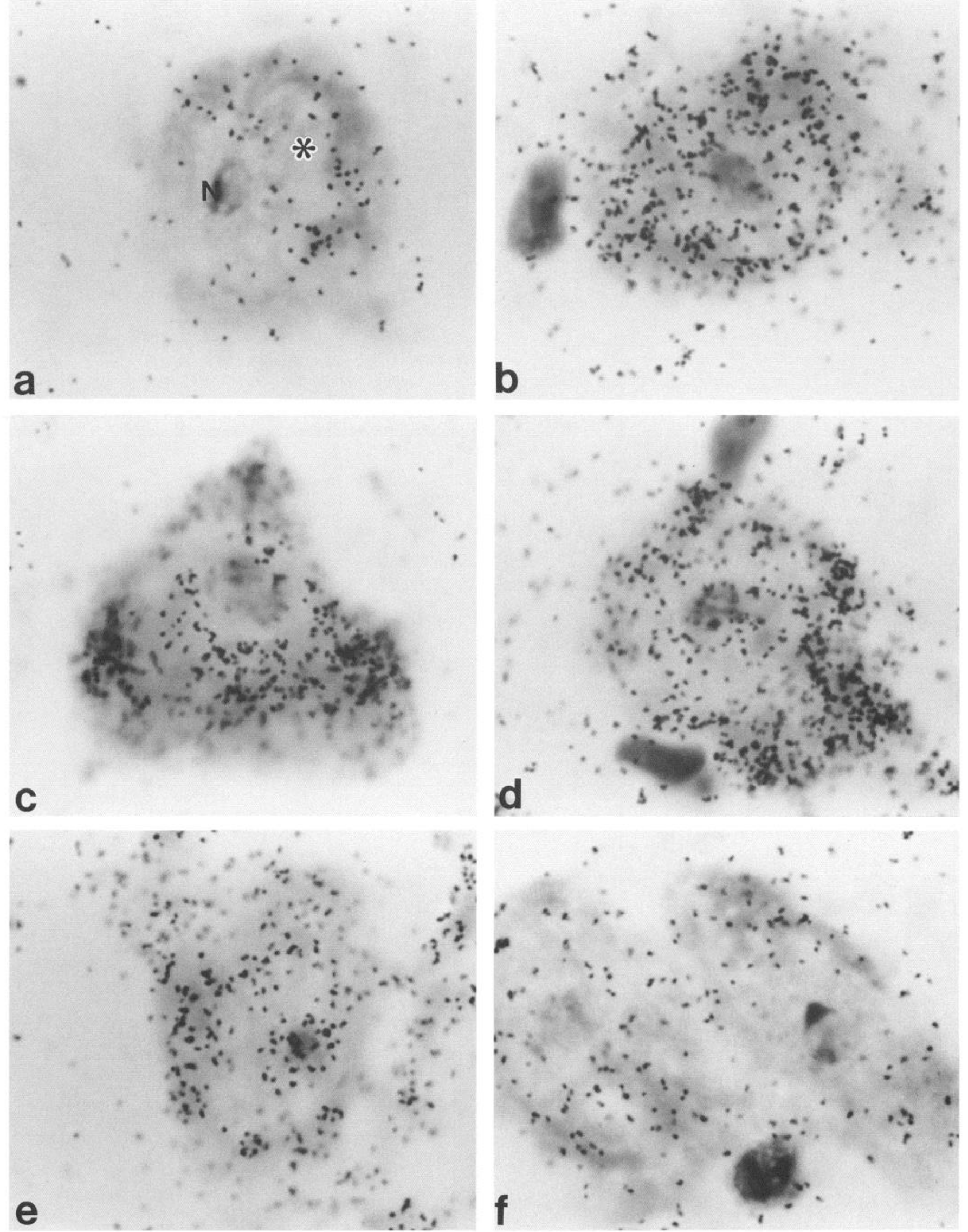

Figure 5. Autoradiographs of facial motoneurons following in situ hybridization with the 28S rDNA probe. $a$, Control neuron from a TP-treated animal. $N$, nucleolus; *, nucleus. $b-f$, Neurons from TP-treated animals at $6 \mathrm{hr}$, and $1,2,7$, and $14 \mathrm{~d}$, respectively, after facial nerve severance. 


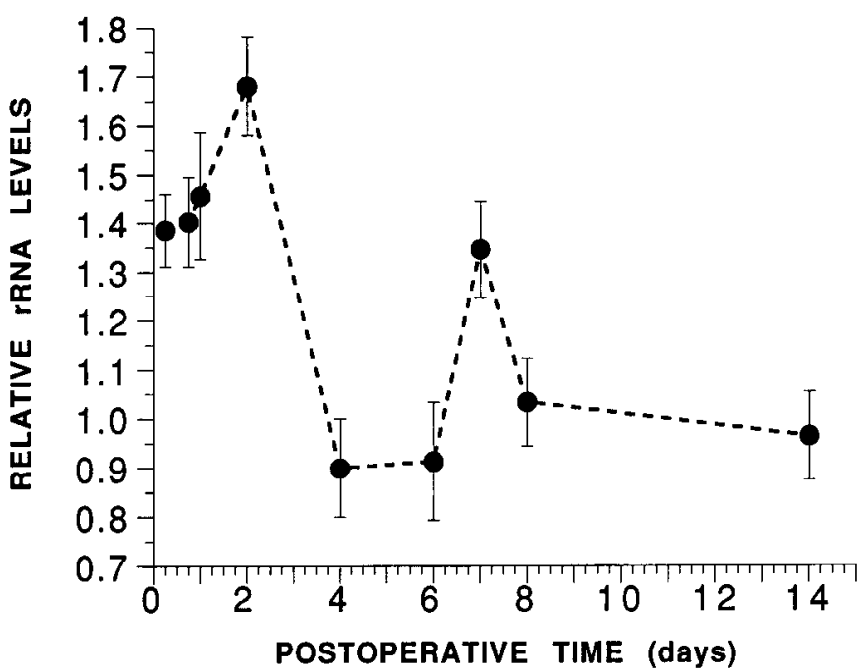

Figure 6. Effects of axotomy plus TP on levels of hybridizable rRNA in injured hamster facial motoneurons as a function of postoperative time. The data are expressed as ratios of averages of numbers of grains/ neuron from axotomized and control facial nuclear groups from hormone-treated animals.

the entire regenerative period. Measurements of somal area in TP-treated animals were determined using the computerized imaging system (Table 1). Administration of the hormone at the time of injury significantly altered the neuronal swelling response to injury. As early as $18 \mathrm{hr}$ after axotomy plus TP, a significant increase in neuronal size, relative to the unoperated controls, was seen $(p<0.05)$. However, unlike axotomy alone, this increase in neuronal size did not remain. No further increases, relative to the unoperated controls from the same animals were identified. Importantly, the increase in swelling at $18 \mathrm{hr}$ in axotomized facial neurons from the TP-treated animals was significantly greater than any of the increases noted in the axotomy alone series $(p<0.05)$. Calculation of the concentration of rRNA levels in individual axotomized HFMN from TPtreated animals was accomplished by determining the grain density or number of grains per square micrometer of somal area, with the data subsequently expressed as ratios of experimental: control (Fig. 7). Changes in the concentration of rRNA paralleled those in levels of rRNA. As with axotomy alone, the addition of TP at the time of injury produced two temporally distinct phases of increased rRNA activity, with both the amount of rRNA and the concentration of rRNA in the injured neurons altered.

\section{Discussion}

The mechanism involved in the initiation of the nerve cell body response to axon injury is currently not known. Elucidation of the earliest events that occur within an injured neuron is of obvious importance in determining the components of such a mechanism. Histological and ultrastructural studies of many different systems have clearly identified the nucleolar reaction as one of the earliest morphological changes to occur in a neuron following axon severance (Lieberman, 1971; Jones and LaVelle, 1986a). Importantly, similarities between nucleolar changes in injured neurons capable of regenerating and in other cell types anabolically stimulated exist, as well as the converse, that is, similarities between nucleolar response patterns in injured neurons with limited or no potential for regeneration and other cell

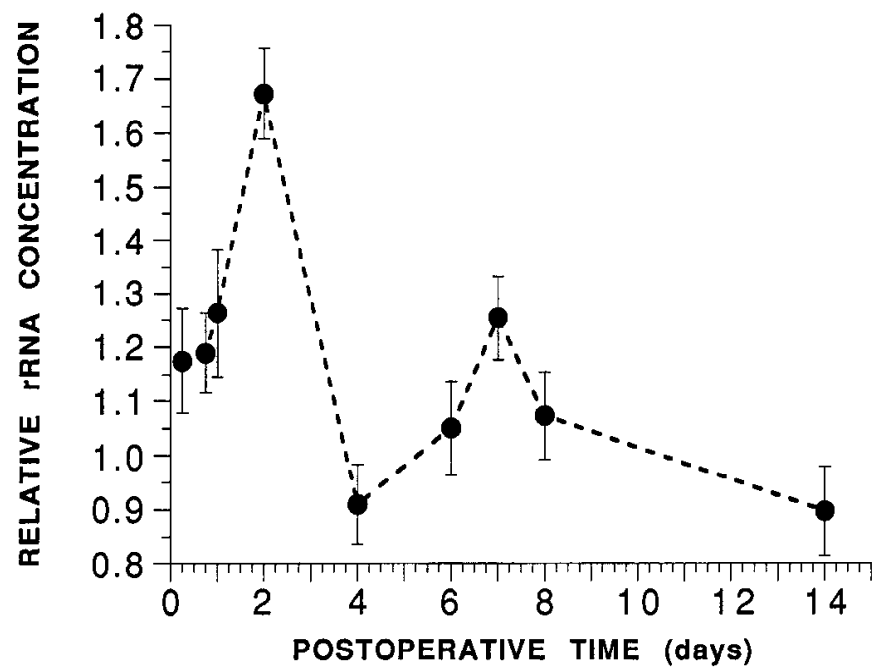

Figure 7. Effects of axotomy plus TP on the concentration of hybridizable rRNA in individual injured hamster facial motoneurons as a function of postoperative time. The data are expressed as ratios of the averages of grain density (number of grains per square micrometer somal area) from axotomizcd and control facial nuclcar groups from hormonetreated animals.

types that have been inhibited metabolically (Busch and Smetana, 1970). Thus, upregulation of the polymerase I system by axonal injury appears to be closely associated with the ability of neurons to initiate a successful regenerative response following axon injury. This concept clearly applies to the HFMN system, in which a link between the type of nucleolar response to injury and the ability to survive and/or regencrate has been established from structural data (Jones and LaVelle, 1986a; Clark et al., 1990, 1991).

The in situ hybridization method is well suited for the study of the regulation of gene expression by various stimuli in neurons, as measurements of individual RNA species can be resolved at the level of the single cell. In the present study, in situ hybridization in conjunction with ribosomal DNA probes complementary to stable ribosomal RNA sequences was utilized to map the early molecular responses of individual axotomized HFMN, and to determine the effects of a neurotrophic agent, $\mathrm{TP}$, on the nerve cell body response to injury. The results provide the first molecular details of the nucleolar response following axotomy in a system with both a robust capacity to regenerate and a pronounced nucleolar reactive pattern (LaVelle and LaVelle, 1984; Jones and LaVelle, 1986a), as well as demonstrate that administration of gonadal steroids at the time of injury can significantly augment the nervous system's response to peripheral nerve damage.

Quantitative assessment of three parameters, levels of rRNA and concentration of $r$ RNA in individual neurons, and neuronal size, was accomplished across early postoperative time points ranging from 6 to $24 \mathrm{hr}$, and throughout the regenerative period of $14 \mathrm{~d}$. Pronounced alterations in the amount of rRNA occurred between 18 and $24 \mathrm{hr}$ after facial nerve severance, with the peak increase in rRNA levels occurring at $24 \mathrm{hr}$. rRNA concentration rose more slowly and peaked several days later. Comparison of this data with the effects of facial nerve severance on nucleolar ultrastructure and neuronal incorporation of tritiated uridine indicates that the molecular changes in nucleolar functioning precede, by a full day, any changes in nucleolar size, morphology, or levels of total RNA (Jones and LaVelle, 1987). The 
lesions in the hamster were always confined to the facial nerve at its exit from the stylomastoid foramen, in order to maintain uniformity of the injury site across these studies. This is important, since variations in lesion site distance from the cell body will significantly alter the time course of events after injury (Lieberman, 1974). Thus, the emerging picture from this injury model indicates that axotomy-induced changes in gene expression are well advanced before associated structural signs occur within the injured cells. This idea is supported from biochemical and metabolic studies that indicate that ornithine decarboxylase activity and 2-deoxyglucose utilization increase well in advance of chromatolysis (Kreutzberg and Emmert, 1980; Wells, 1987).

Whether the axotomy-induced increases in ribosome levels and cellular concentration of rRNA found in this study are due to transcriptional activation of the ribosomal genes or to alterations in ribosome stability is not known, but this question represents an important future direction of this study. Regulation of ribosome biogenesis is an ongoing process in proteinsecretory cells such as neurons and requires the coordinated transcriptional regulation of a number of different sets of rRNA genes (Hadjiolov, 1985). The nature of the structural changes in the nucleoli of injured HFMN (Kinderman and LaVelle, 1976; Jones and LaVelle, 1986a; Clark et al., 1991), as well as other neuronal cell types (Lieberman, 1971), argues toward an effect of injury on transcriptional activation of the ribosomal genes, but does not preclude concomitant changes in the stability of mature ribosomes. As reviewed by Sollner-Webb and Tower (1986), the correlation of chromatin-bound RNA polymerase I molecules and the rate of rRNA synthesis, as well as the overall availability of polymerase I in cells, suggests that stimulus-induced alterations in the rate of rRNA production occur at the level of transcription.

As shown by studies ranging from the structural to the molecular level, gonadal steroids exert profound trophic influences on the brain and spinal cord (Cohen and Pfaff, 1981; Jones et al., 1985, 1986b, 1990; Gould et al., 1990; Ferreira and Caceres, 1991). In view of the apparent trophic actions of androgens on motoneurons, we recently completed a series of experiments in which we identified a role for TP in facilitating the reparative response of injured facial neurons (Kujawa et al., 1989, 1991; Kujawa and Jones, 1990). Administration of TP at the time of facial nerve crush injury at the level of the stylomastoid foramen accelerates both functional recovery from facial paralysis and the rate of regeneration of the fastest growing axons. This is in accord with previous work by $\mathrm{Yu}$ (1982), in which an increase in the number of HRP-labeled hypoglossal neurons was found in TP-treated animals after crush injury of the hypoglossal nerve. We proposed that a possible mechanism for the observed accelerated regeneration rates in the facial injury model could involve hormonal modulation of a genomic "switch" from a normal to a reparative state. We tested that hypothesis in this study by assaying the temporal effects of TP on the polymerase I system in injured facial motoneurons following facial nerve severance. The results indicate that TP markedly enhances the nerve cell body response to injury by essentially priming the injured neuron. By $6 \mathrm{hr}$ postaxotomy plus hormone, the levels of ribosomal RNA were increased $39 \%$, relative to the unoperated, hormone-treated controls. These levels approximated the maximum of $48 \%$ reached at $24 \mathrm{hr}$ in the axotomized, nonhormone-treated neurons. Exposure to TP also increased the extent of change in rRNA levels after injury $(68 \%$ with hormone as compared to $48 \%$ without hormone). Thus, aspects of cellular functioning affected by gonadal steroids under steady state conditions, such as regulation of the polymerase I system (Whelly, 1985; Jones et al., 1986a, 1990), are also significantly affected by steroids under stress conditions. It appears that testosterone activates molecular events associated with the injury response in accordance with the acceleration in functional recovery and regeneration previously documented in this system (Kujawa et al., 1989, 1991; Kujawa and Jones, 1990). Determining if the correlation between the rapid induction of the polymerase I system and the acceleration in the rate of facial nerve regeneration by testosterone is a causal one represents a future direction of this study.

Neuronal hypertrophy has been shown to be a component of the nerve cell body response to injury in many systems, including IIFMN (LaVelle and LaVelle, 1958b; Lieberman, 1971; Grafstein, 1975). As would be predicted from previous studies (I.aVelle and IaVelle, 1958b), axotomy produced significant increases in neuronal size beginning at $1 \mathrm{~d}$ postoperative. The addition of TP at the time of injury resulted in facial neuronal hypertrophy by $18 \mathrm{hr}$, with the amount of swelling significantly greater than that which occurred later with injury alone. This lends further support to the idea that TP acts to enhance the axon reaction in this cell type. Interestingly, the effect of TP plus axotomy on neuronal size was short-lived, relative to the effects of axotomy alone. While the reasons for this are not clear, it suggests that there is a relatively narrow "window" of time for the steroid to alter cellular events conducive to regeneration. Substantiating this argument is evidence from behavioral studies indicating that delayed exposure to the hormone after axotomy eliminates altogether the accelerative effect of the steroid on recovery from facial paralysis (Kujawa and Joncs, 1990).

As evidenced at both morphological and molecular levels, then, testosterone shortens the time interval between axon disconnection and onset of the axon reaction. How this occurs is not known, although several plausible explanations exist. First, the posttraumatic events could be the same but temporally stimulated in a coordinated manner. Conversely, exposure to the hormone could result in a "bypassing" of several steps in the injury response and in some way trigger the production of new ribosomes through an alternate pathway. This leads to the question of exactly what step in ribosome biogenesis is being regulated by injury alone, an issue that needs to be determined first.

An additional, unexpected finding of this study was that axotomy induced a secondary phase of metabolic activity that occurred during the later postoperative stages, which correlate with previously defined points at which functional recovery occurs after crush injury (Kujawa et al., 1989). Of particular significance is that the secondary phase mirrored the first, in each experimental series. In both the axotomy and hormone-treated series, a transition point at the end of the first postoperative week was observed. The presence of two phases of the axon reaction has been documented by others, principally with regard to RNA synthesis (Langford et al., 1980; Austin et al., 1983; Wells, 1984, 1987). The significance of these two phases is unclear; however, it may be that the early phase represents events associated with generalized cellular stress, and the later phase represents events focused on rebuilding the severed axon. Supporting this idea are data from various systems, including the HFMN, which demonstrate that heat shock or stress protein mRNA levels are markedly elevated within hours after injury (Brown et al., 1989; Gower et al., 1989; New et al., 1989), and studies of cytoskeletal changes after injury, which indicate that 
tubulin mRNA levels are upregulated in the later postoperative stages (Oblinger et al., 1989; Wong and Oblinger, 1990).

In summary, these data establish the first molecular correlates to what has been historically defined from a morphological perspective and, as such, a structure-function framework in which to identify the early events associated with neuronal survival and regeneration after injury. Mechanistic evidence has been presented that indicates that the gonadal steroid testosterone enhances the nerve cell body response to injury by triggering the onset and increasing the magnitude of the nucleolar reaction observed with axotomy. Whether this neurotrophic agent alters the composition of the signaling pathway associated with initiating the injury response or accelerates a preexisting sequence of events associated with axotomy remains to be determined.

\section{References}

Ausebel FM, Brent R, Kingston RE, Moore DD, Seidman JS, Smith JA, Struhl K (1989) Current protocols in molecular biology, Sec 4.9.1-4.9.8. New York: Greene and Wiley-Interscience.

Austin L, Moses EK, Langford CJ (1983) Macromolccular changes during nerve regeneration: changes in small molecular weight RNAs. In: Nervous system regeneration (Perex-Polo JR, Hashim GH, Giuffrida Stella AM, eds), pp 471-477. New York: Liss.

Brown IR, Rush S, Ivy GO (1989) Induction of a heat shock gene at the site of tissue injury in the rat brain. Neuron 2:1559-1564.

Busch H, Smetana K (1970) The nucleolus. New York: Academic.

Chikaraishi DM, Buchannan L, Danna KJ, Harrington CA (1983) Genomic organization of rat rRNA. Nucleic Acids Res 10:1277-1284.

Chomczynski P, Sacchi N (1987) Single-step method of RNA isolation by acid guanidinium thiocyanate-phenol-chloroform extraction. Anal Biochem 162:156-159.

Clark P, Jones KJ, LaVelle A (1990) Ultrastructural and morphometric analysis of nucleolar and nuclear changes during the early growth period in hamstcr facial ncurons. J Comp Neurol 302:749760.

Clark P, Jones KJ, LaVelle A (1991) Ultrastructural changes in the nucleolus of facial motor neurons following axotomy during an early critical period in development. J Comp Neurol 312:132-144.

Cohen RS, Pfaff DW (1981) Ultrastructure of neurons in the ventromedial nucleus of the hypothalamus in ovariectomized rats with or without estrogen treatment. Cell Tissue Res 217:451-470.

Dabeva MD, Dudov KP, Hadjiolov AA, Stoykova AS (1978) Quantitative analysis of rat liver nucleolar and nucleoplasmic rRNA. Biochem J 171:367-374.

Ferreira A, Caceres A (1991) Estrogen-enhanced neurite outgrowth: evidence for a selective induction of tau and stable microtubules. J Neurosci 11:392-400.

Gould E, Woolley CS, Frankfurt M, McEwen BS (1990) Gonadal steroids regulate dendritic spine density in hippocampal pyramidal cells in adulthood. J Neurosci 10:1286-1291.

Gower DJ, Hollman C, Lee KS, Tytell M (1989) Spinal cord injury and the stress protein response. J Neurosurg 70:605-611.

Grafstein B (1975) The nerve cell body response to axotomy. Exp Neurol 48:32-51.

Hadjiolov AA (1985) The nucleolus and ribosome biogenesis. New York: Springer.

Hawkins RA, Mans AM (1989) Determination of cerebral glucose use in rats using $\left[{ }^{14} \mathrm{C}\right]$ glucose. In: Neuromethods 11 , Carbohydrates and energy metabolism, pp 195-230. Clifton, NJ: Humana.

Jones KJ (1993) Gonadal steroids and neuronal regeneration: a therapeutic role. In: Advances in neurology, Vol 59 (Seil F, ed), pp 227240. New York: Raven.

Jones KJ, LaVelle A (1986a) Differential effects of axotomy on immature and mature hamster facial neurons: a time course study of initial nucleolar and nuclear changes. J Neurocytol 15:197-206.

Jones KJ, LaVelle A (1986b) Ultrastructural changes in the nucleoplasm of hamster facial neurons during a postnatal maturation period. Brain Res 377:119-126.

Jones KJ, LaVelle A (1987) Differential effects of axotomy on immature and mature hamster facial neurons: a tritiated-uridine autoradiographic study. Metab Brain Dis 2:259-269.

Jones KJ, Pfaff DW, McEwen BS (1985) Early estrogen-induced nu- clear changes in rat hypothalamic ventromedial neurons: an ultrastructural and morphometric analysis. J Comp Neurol 239:255-267.

Jones KJ, Chikaraishi DM, Harrington CA, McEwen BS, Pfaff DW (1986a) In situ hybridization detection of estradiol-induced changes in ribosomal RNA levels in rat brain. Mol Brain Res 1:145-152.

Jones KJ, McEwen BS, Pfaff DW (1986b) Regional specificity in estradiol effects on ${ }^{3} \mathrm{H}$-uridine incorporation in rat brain. Mol Cell Endocrinol 45:57-63.

Jones KJ, Harrington CA, Chikaraishi DM, PfaffDW (1990) Estradiol regulation of ribosomal RNA processing in rat ventromedial hypothalamic neurons: early detection by quantitative in situ hybridization. J Neurosci 10:1515-1521.

Kinderman NB, Jones KJ (1991) Testosterone effects on ribosomal RNA levels in injured peripheral motor neurons: a preliminary report. Metab Brain Dis 6:157-164.

Kinderman NB, LaVelle (1976) Ultrastructural changes in the developing nucleolus following axotomy. Brain Res 108:237-247.

Kreutzberg GW, Emmert H (1980) Glucose utilization of motor nuclei during regeneration: $\mathrm{a}\left[{ }^{14} \mathrm{C}\right] 2$-deoxyglucose study. Exp Neurol 70:712716.

Krey LC, McGinnis MY (1990) Time courses of the appearance/ disappearance of nuclear androgen + receptor complexes in the brain and adenohypophysis following testosterone administration/withdrawal to castrated male rats: relationships with gonadotropin secretion. J Steroid Biochem 35:403-408.

Kujawa KA, Jones KJ (1990) Testosterone-induced acceleration of recovery from facial paralysis in male hamsters: temporal requirements of hormone exposure. Physiol Behav 48:765-768.

Kujawa KA, Kinderman NB, Jones KJ (1989) Testosterone-induced acceleration of recovery from facial paralysis following crush axotomy of the facial nerve in male hamsters. Exp Neurol 105:80-85.

Kujawa KA, Emeric E, Jones KJ (1991) Testosterone differentially regulates the regenerative properties of injured hamster facial motoneurons. J Neurosci 11:3898-3906.

Langford CJ, Scheffer JW, Jeffrey PL, Austin L (1980) The in vitro synthesis of RNA within the rat nodose ganglion following vagotomy. J Neurochem 34:531-539.

LaVelle A, LaVelle FW (1958a) The nucleolar apparatus and neuronal reactivity to injury during development. J Exp Zool 137:285-315.

LaVelle A, LaVelle FW (1958b) Neuronal swelling and chromatolysis as influenced by the state of cell development. Am J Anat 102:219241.

LaVelle A, LaVelle FW (1984) Neuronal reaction to injury during development. In: Early brain damage, neurobiology and behavior, Vol 12 (Almki CR, Finger S, eds), pp 3-16. New York: Academic.

Lieberman AR (1971) The axon reaction: a review of the principal features of perikaryal responses to axon injury. Int Rev Neurobiol $14: 49-125$.

Lieberman AR (1974) Some factors affecting retrograde neuronal responses to axonal lesions. In: Essays on the nervous system (Bellairs R, Gray EG, eds), pp 71-105. New York: Oxford UP.

McLoon LK, LaVelle A (1981) Long-term effects of regeneration on nucleolar morphology after facial nerve injury during development. Exp Neurol 73:762-774.

New GA, Hendrickson BR, Jones KJ (1989) Induction of heat shock protein 70 mRNA in adult hamster facial nuclear groups following axotomy of the facial nerve. Metab Brain Res 4:273-279.

Oblinger MM, Szumlas RA, Wong J, Liuzzi FJ (1989) Changes in cytoskeletal gene expression affect the composition of regenerating axonal sprouts elaborated by dorsal root ganglion neurons in vivo. $\mathbf{J}$ Neurosci 9:2645-2653.

Pfaff DW, Keiner M (1973) Atlas of estradiol-concentrating cells in the central nervous system of the female rat. J Comp Neurol 151: 121-158.

Simerly RB, Chang C, Muramatsu M, Swanson LW (1990) Distribution of androgen and estrogen receptor mRNA-containing cells in the rat brain: an in situ hybridization study. J Comp Neurol 294:7695.

Sokal RR, Rohlf FJ (1981) Biometry, 2d ed. San Francisco: Freeman. Sollner-Webb B, Tower J (1986) Transcription of cloned eukaryotic ribosomal RNA genes. Annu Rev Biochem 55:801-830.

Watson WE (1968) Observations on the nucleolar and total cell body nucleic acid of injured nerve cells. J Physiol (Lond) 196:655-676.

Wells MR (1984) Alterations of $\left[{ }^{3} \mathrm{H}\right]$ actinomycin $D$ binding to axotomized dorsal root ganglion cell nuclei: an autoradiographic method 
to detect changes in chromatin structure and RNA synthesis. Exp Neurol 86:303-312.

Wells MR (1987) Changes of ornithine decarboxylase activity in dorsal root ganglion cells after axon injury: possible relationship to alterations in neuronal chromatin. Exp Neurol 95:313-322.

Whelly SM (1985) Regulation of uterine nucleolar RNA synthesis by estrogens. Biol Reprod 33:1-10.
Wong J, Oblinger MM (1990) A comparison of peripheral and central axotomy effects on neurofilament and tubulin gene expression in rat dorsal root ganglion neurons. J Neurosci 10:2215-2222.

Yu WHA (1982) Effect of testosterone on the regeneration of the hypoglossal nerve in rats. Exp Neurol 77:129-141.

Yu WHA, McGinnis MY (1986) Androgen receptor levels in cranial nerve nuclei and tongue muscles in rats. J Neurosci 6:1302-1307. 